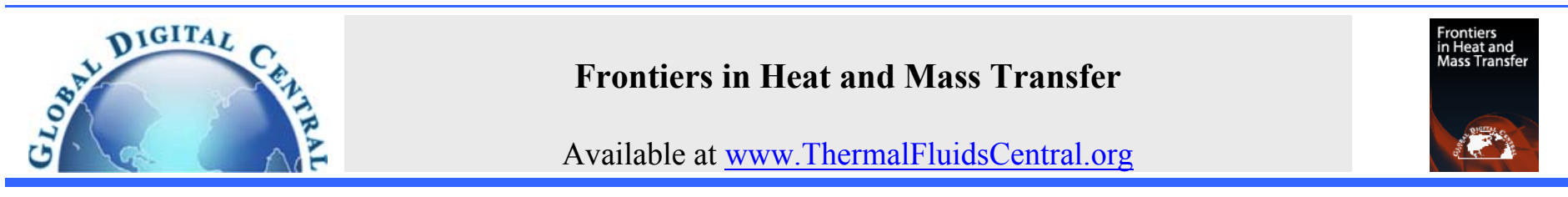

\title{
EFFECT OF MAGNETIC FIELD INCLINATION ON MAGNETO- CONVECTIVE INDUCED IRREVERSIBILITIES IN A CNT-WATER NANOFLUID FILLED CUBIC CAVITY
}

\author{
Abdullah A.A.A. Al-Rashed ${ }^{\mathrm{a}}$, Lioua Kolsi ${ }^{\mathrm{b}, \mathrm{d},{ }^{*}, \text { K. Kalidasan }}{ }^{\mathrm{c}}$, Chemseddine Maatki $^{\mathrm{d}}$, Mohamed Naceur Borjini ${ }^{\mathrm{d}}$, Mohamed Aichouni ${ }^{\mathrm{b}}$ and P. Rajesh \\ Kanna $^{\mathrm{e}}$ \\ ${ }^{a}$ Dept. of Automotive and Marine Engineering Technology, College of Technological Studies, the Public Authority for Applied Education and \\ Training, Kuwait \\ ${ }^{b}$ College of Engineering, Mechanical Engineering Department, Haïl University, Haïl City, Saudi Arabia \\ ${ }^{c}$ Department of Civil Engineering, Arulmigu Palaniandavar Polytechnic College, Palani, Tamilnadu - 624 601, India. \\ ${ }^{d}$ Unité de Métrologie et des Systèmes Énergétiques, École Nationale d'Ingénieurs, Monastir, University of Monastir, Tunisia \\ ${ }^{e}$ Department of Mechanical Engineering, Velammal College of Engineering and Technology, Madurai, Tamilnadu - 625 009, India.
}

\begin{abstract}
A finite volume based three dimensional numerical analysis is performed on the effect of angle of inclination of the external magnetic force on entropy generation due to natural convection inside the cubical cavity filled with CNT - water nanofluid. The governing equations are numerically solved by vorticity - vector potential formalism. The vertical walls of enclosure are differentially heated and the horizontal walls are adiabatic. The effect due to Rayleigh number $\left(10^{3} \leq \mathrm{Ra} \leq 10^{5}\right)$, Hartmann number $(0 \leq \mathrm{Ha} \leq 100)$, angle of inclination of external magnetic field $\left(0^{\circ} \leq \alpha \leq 90^{\circ}\right)$ and volumetric fraction $(0 \leq \varphi \leq 0.05)$ of CNT particles are investigated. The results of irreversibility process with single phase model are illustrated with entropy generation and Bejan number. The effect of angle of inclination is more pronounced when Rayleigh number is $10^{5}$.

Keywords: Magnetoconvection, Entropy generation, Natural convection, Inclined Magnetic field
\end{abstract}

\section{INTRODUCTION}

Magnetohydrodynamic (MHD) flow inside the enclosure is the attraction of many recent researchers due its applications in many vital industries like astrophysics, geophysics, aeronautics, metallurgy, chemical and petroleum industries, crystal growth in liquid, cooling of nuclear reactor, microelectronic devices and solar technology (Seth et al., 2016; Mahmoudi et al., 2013). To conserve the energy, it is essential to reduce the entropy generation inside the system. The reduction of process of irreversibility in a system indicates that it is energetically more efficient. In a MHD natural convection, the flow is influenced by the magnetically induced Lorentz forces and thermally generated buoyancy forces. Some studies on the entropy generation due to natural convection flow were performed by (Bejan, 1979; Oztop and Al-Salem, 2012; Mahian et al., 2012; Khorasanizadeh et al., 2013).

Many fluids like water have very low thermal conductivity and consume more energy. The easiest way to improve the thermal conductivity of the fluid is adding an ultra-fine solid like nano particles. The ferrous nanoparticles have high electrical conductivity and generate more Lorentz forces. The studies using CNT as nanoparticles were carried by (Glory et al, 2008; Ding et al., 2006; Kalidasan and Kanna, 2016; Esfe et al., 2016). Abolbashari et al. (2014) performed entropy analysis for an unsteady MHD flow using different nanofluid indicates that Joule dissipation irreversibility and the averaged entropy generation number are the increasing function of the Hartmann number. Mahmud and Fraser (2004) investigated numerically the First and Second Laws of thermodynamics aspects of fluid flow and heat transfer inside a porous cavity subjected to a magnetic field acting along the direction of the gravity and indicated that increases in the value of $\mathrm{Ha}$ retards the fluid motion inside the cavity. Abu - Nada and Oztop (2009) studied the effect of inclination angle of enclosure on natural convection and proposed the inclination angle as a control parameter for fluid flow and heat transfer. Ching - Chang Cho (2016) investigated the influence of magnetic field on natural convection and entropy generation using nanofluid on a wavy surface and reported that the Bejan number increases with an increasing Hartmann number due to the repression of convective heat transfer. Ellahi et al. (2015) analyzed the shape effects of nano particles on entropy generation and revealed that the velocity decreases maximum by bricks shaped nanoparticles than other shapes like cylindrical and platelets. Ibanez et al. (2006) applied entropy generation minimization method to the optimization of a magnetohydrodynamic flow between two infinite parallel walls of finite electrical conductivity and indicated that the energy loss in the system can be minimized by cooling the walls externally in an asymmetric way. Kefayati (2016) performed the research on entropy generation in an open cavity filled with power - law fluids and concluded that Bejan number declines significantly with the augmentation of thermal Rayleigh number due to fluid friction. Mejri et al. (2014) examined the laminar natural convection and entropy generation in a square enclosure filled with water $\mathrm{Al}_{2} \mathrm{O}_{3}$ nanofluid and

\footnotetext{
"Corresponding author. Email: lioua_enim@yahoo.fr.
} 
subjected to a magnetic field.

They informed that for all the phase deviation, the strength of the local entropy generation decreases with the increases of the Hartmann number. Aghaei et al. (2016) performed the MHD mixed convection with nanofluid inside the trapezoidal enclosure and reported that increasing the strength of magnetic field reduced the strength of flow and the flow tends toward the natural convection and finally toward pure conduction. Mojumder et al. (2016) studied the entropy generation in a half - moon shaped cavity with ferrouid and reported that $R a$ should be kept as high as possible while $\mathrm{Ha}$ should be kept as low as possible at moderate inclination angle to escalate the heat transfer rate while optimizing the entropy.

Most of the researches in the past were performed with two dimensional analyses. But three dimensional analysis represents the true picture of the system and yields accurate results. Kolsi et al. (2010) investigated the effect of external magnetic field on natural convection in a cubical cavity and found that the entropy generated by friction and Joule effect is more influenced by the magnetic field than that generated by thermal dissipation. Hayat et al. (2015) three dimensionally analyzed the MHD flow of nanofluid in convective conditions and concluded that the velocity profile decreased at higher volumetric fractions of nanoparticles. Kolsi et al. (2016a) numerically performed the studies on entropy generation on a cubical cavity with twin adiabatic blocks and found that the locally generated entropy due to friction surges due to the increase in the volumetric fraction of nanoparticles. Maatki et al. (2014) examined the entropy generation in a three dimensional double diffusive natural convection and highlighted that entropy is a good tool to observe the energy losses and to control the system efficiency.

The combined effects of gravitational force, Lorentz force and buoyancy force on the entropy generation needs to be investigated to design an economical and efficient system. CNT possess high thermal as well as electrical conductivity and combined well with water during convection by virtue of its lower density and particle distribution. Also, MHD induced natural convection is used in many industrial applications like crystal growth, polymer industries and metallurgy. The nuclei of the present research is to enhance the efficiency of the magneto-thermofluidic systems by minimizing the process of irreversibility on the cubical enclosure filled with CNT-nanofluid and exposed to an inclined external magnetic field.

\section{PROBLEM STATEMENT}

The graphical representation of the system is illustrated in fig. 1. The enclosure has a hot wall on the left side and cold wall on the right side. The horizontal walls are adiabatic. An external magnetic field is located at the center of the left hot wall which induced the magnetic convection at an angle of $\alpha$. The enclosure is filled with CNT-water nanofluid with $\operatorname{Pr}=6.2$. The thermophysical properties pure fluid (water) and CNT particles are presented in table 1 . The flow is considered as threedimensional, laminar, incompressible and unsteady. Boussinesq approximation is applied to assume the constant density of the nanofluid.

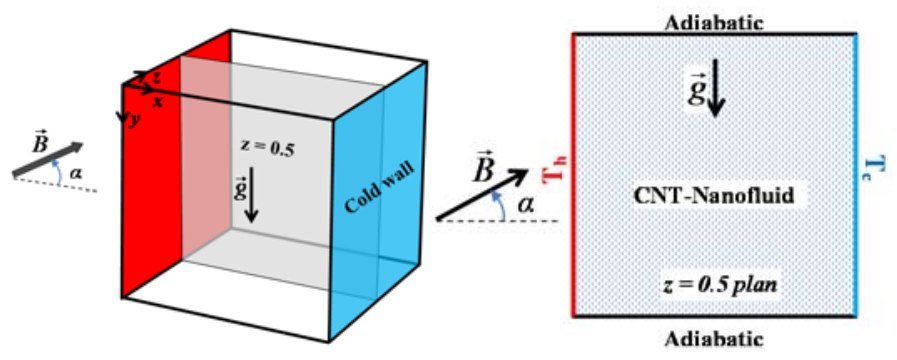

Fig. 1 Geometrical representation of the Problem

\subsection{Governing Equations}

Equations governing the studied configuration were written using the $3 \mathrm{D}$ vorticity-vector potential formalism. This formalism allows the elimination of the pressure which is delicate to treat. Vorticity and vector potential are defined respectively by the following two relations: $\vec{\omega}^{\prime}=\vec{\nabla} \times \vec{V}^{\prime}$ and $\vec{V}^{\prime}=\vec{\nabla} \times \vec{\psi}^{\prime}$

$t^{\prime}, \vec{V}^{\prime}, \vec{\psi}^{\prime}, \vec{\omega}^{\prime}, \vec{J}^{\prime}, \vec{B}^{\prime}$ and $\Phi^{\prime}$ are put in their dimensionless form by $l^{2} / \alpha$ $\alpha / l, \alpha l^{2} / \alpha, \sigma \cdot v_{0} . B_{0} B_{0}$ and $l \cdot v_{0} . B_{0}$ respectively, and the dimensionless temperature is written as: $T=\left(T^{\prime}-T_{c}{ }^{\prime}\right) /\left(T_{h}{ }^{\prime}-T_{c}{ }^{\prime}\right)$

Table 1. Thermophysical properties of water and CNT nanoparticles (Job and Gunakala (2016))

\begin{tabular}{c|c|c}
\hline Physical properties & Water & CNT \\
\hline$C_{p}(\mathrm{~J} / \mathrm{kg} \cdot \mathrm{K})$ & 4179 & 425 \\
$\rho\left(\mathrm{kg} / \mathrm{m}^{3}\right)$ & 997.1 & 2600 \\
$k(\mathrm{~W} / \mathrm{m} \cdot \mathrm{K})$ & 0.613 & 6600 \\
$\beta\left(K^{-1}\right)$ & $21 \times 10^{-5}$ & $1.6 \times 10^{-6}$ \\
$\sigma\left(\Omega^{-1} \cdot \mathrm{m}^{-1}\right)$ & 0.05 & $4.8 .10^{-7}$ \\
\hline
\end{tabular}

The system of equations governing the phenomenon is:

$-\vec{\omega}=\nabla^{2} \vec{\psi}$

$$
\begin{aligned}
\frac{\partial \vec{\omega}}{\partial t}+(\vec{V} \cdot \nabla) \vec{\omega}=(\vec{\omega} \cdot \nabla) \vec{V} & +\frac{v_{n f}}{v_{f}} \operatorname{Pr} \cdot \nabla^{2} \vec{\omega}-\frac{\beta_{n f}}{\beta_{f}} \operatorname{Ra} \operatorname{Pr} \nabla \times T \vec{g} \\
& +\frac{\rho_{f}}{\rho_{n f}} \cdot \frac{\sigma_{n f}}{\sigma_{f}} H a^{2} \cdot \operatorname{Pr} . \nabla \times\left(\vec{j} \times \vec{e}_{B}\right)
\end{aligned}
$$

$$
\begin{aligned}
& \frac{\partial T}{\partial t}+\vec{V} \cdot \nabla T=\frac{\alpha_{n f}}{\alpha_{f}} \nabla^{2} T \\
& \vec{j}=-\vec{\nabla} \Phi+\vec{V} \times \vec{e}_{B} \\
& \vec{\nabla}^{2} \Phi=\vec{\nabla} \cdot(\vec{V} \times \vec{B})=-\vec{e}_{B} \cdot \vec{w} \\
& \text { With } \vec{e}_{B}=\cos (\alpha) \cdot \vec{e}_{x}+\sin (\alpha) \cdot \vec{e}_{y}
\end{aligned}
$$

In these equations, the dimensionless $\mathrm{Pr}, \mathrm{Ra}$ and $\mathrm{Ha}$ numbers are respectively defined as:

$$
\operatorname{Pr}=\frac{v_{f}}{\alpha_{f}}, R a=\frac{g \cdot \beta_{f} \cdot \Delta T \cdot l^{3}}{v_{f} \cdot \alpha_{f}} \text { and } H a=B_{0} L \sqrt{\frac{\sigma_{f}}{\rho_{f} v_{f}}}
$$

A detailed description of the mathematical formulation of MHD natural convection is presented in the work of Kolsi et al (2016.b)

The effective density of the nanofluid is given by Kahveci (2010) as:

$$
\rho_{n f}=(1-\varphi) \rho_{f}+\varphi \rho_{s}
$$

The heat capacitance of the nanofluid is expressed as Kahveci (2010):

$$
\left(\rho C_{p}\right)_{n f}=(1-\varphi)\left(\rho C_{p}\right)_{f}+\varphi\left(\rho C_{p}\right)_{s}
$$

The effective thermal conductivity of the nanofluid is approximated by Xue (2005) as:

$$
\frac{k_{n f}}{k_{f}}=\frac{1-\varphi+2 \varphi \frac{k_{s}}{k_{s}-k_{f}} \ln \left(\frac{k_{s}+k_{f}}{2 k_{f}}\right)}{1-\varphi+2 \varphi \frac{k_{f}}{k_{s}-k_{f}} \ln \left(\frac{k_{s}+k_{f}}{2 k_{f}}\right)}
$$

The effective dynamic viscosity of the nanofluid is given by Brinkman model as:

$$
\mu_{n f}=\frac{\mu_{f}}{(1-\varphi)^{2.5}}
$$

The electrical conductivity of a nanofluid is given by Mahmoudi et al. (2013): 


$$
\sigma_{n f}=\sigma_{f}\left[1+\frac{3 \cdot \varphi \cdot\left(\frac{\sigma_{s}}{\sigma_{f}}-1\right)}{\left(\frac{\sigma_{s}}{\sigma_{f}}+2\right)-\varphi \cdot\left(\frac{\sigma_{s}}{\sigma_{f}}-1\right)}\right]
$$

In the presence of a magnetic field the generated entropy is written in the following form Kolsi et al. (2010):

$$
\begin{aligned}
& S_{\text {gen }}^{\prime}=\left\{\frac{k_{n f}}{T_{0}^{2}}\left[\left(\frac{\partial T^{\prime}}{\partial x^{\prime}}\right)^{2}+\left(\frac{\partial T^{\prime}}{\partial y^{\prime}}\right)^{2}+\left(\frac{\partial T^{\prime}}{\partial z^{\prime}}\right)^{2}\right]\right\}+ \\
& \frac{\mu_{n f}}{T_{0}}\left\{2\left[\left(\frac{\partial V_{x}^{\prime}}{\partial x^{\prime}}\right)^{2}+\left(\frac{\partial V_{y}^{\prime}}{\partial y^{\prime}}\right)^{2}+\left(\frac{\partial V_{z}^{\prime}}{\partial z^{\prime}}\right)^{2}\right]+\right. \\
& \left.\left(\frac{\partial V_{y}^{\prime}}{\partial x^{\prime}}+\frac{\partial V_{x}^{\prime}}{\partial y^{\prime}}\right)^{2}+\left(\frac{\partial V_{z}^{\prime}}{\partial y^{\prime}}+\frac{\partial V_{y}^{\prime}}{\partial z^{\prime}}\right)^{2}+\left(\frac{\partial V_{x}^{\prime}}{\partial z^{\prime}}+\frac{\partial V_{z}^{\prime}}{\partial x^{\prime}}\right)^{2}\right\}
\end{aligned}
$$

The first term represents the generated entropy due to temperature gradient, the second that due to the friction effects and the last that due to the presence of the magnetic field (Joule effect).

The dimensionless local generated entropy $\left(N_{S}\right)$ is written in the following way:

$$
\begin{aligned}
& N_{s}=\frac{k_{n f}}{k_{f}}\left[\left(\frac{\partial T}{\partial x}\right)^{2}+\left(\frac{\partial T}{\partial y}\right)^{2}+\left(\frac{\partial T}{\partial z}\right)^{2}\right] \\
& +\varphi_{S} \frac{\mu_{n f}}{\mu_{f}}\left\{\begin{array}{l}
2\left[\left(\frac{\partial V_{x}}{\partial x}\right)^{2}+\left(\frac{\partial V_{y}}{\partial y}\right)^{2}+\left(\frac{\partial V_{z}}{\partial z}\right)^{2}\right]+ \\
{\left[\left(\frac{\partial V_{y}}{\partial x}+\frac{\partial V_{x}}{\partial y}\right)^{2}+\left(\frac{\partial V_{z}}{\partial y}+\frac{\partial V_{y}}{\partial z}\right)^{2}+\left(\frac{\partial V_{x}}{\partial z}+\frac{\partial V_{z}}{\partial x}\right)^{2}\right]}
\end{array}\right\} \\
& +\varphi_{S} \cdot \frac{\mu_{f}}{\mu_{n f}} \frac{\sigma_{n f}}{\sigma_{f}} H^{2}\left(J_{x}^{2}+J_{y}^{2}+J_{z}^{2}\right)
\end{aligned}
$$

Where $\varphi_{S}=\left(\frac{\alpha}{l \Delta T}\right)^{2} T_{0}$ is the irreversibility coefficient.

The local generated entropy is the sum of three types of entropies; the first one is due to temperature gradients $\left(N_{s-t h}\right)$, the second is due to viscous effects $\left(N_{s-f r}\right)$ and the third due to Joule effect.

The total generated entropy $\left(S_{t o t}\right)$ is given by:

$$
S_{\text {tot }}=\int_{v} N_{s} d v=\int_{v}\left(N_{s-t h}+N_{s-f r}+N_{s-J}\right) d v=S_{t h}+S_{f r}+S_{J}
$$

The Bejan number $(\mathrm{Be})$ is the ratio of heat transfer irreversibility to the total irreversibility as:

$$
B e=\frac{S_{t h}}{S_{t h}+S_{f r}+S_{J}}
$$

The local Nusselt number $(\mathrm{Nu})$ is defined as follows:

$$
N u=\left.\left(\frac{k_{n f}}{k_{f}}\right) \frac{\partial T}{\partial x}\right|_{x=0,1}
$$

The average Nusselt number on the hot wall $\left(N u_{a v}\right)$, is expressed by:

$$
N u_{a v}=\int_{0}^{1} \int_{0}^{1} N u \cdot d y \cdot d z
$$

For each time step, the following convergence criterion is satisfied:

$$
\sum_{i}^{1,2,3} \frac{\max \left|\psi_{i}^{n}-\psi_{i}^{n-1}\right|}{\max \left|\psi_{i}^{n}\right|}+\max \left|T_{i}^{n}-T_{i}^{n-1}\right| \leq 10^{-5}
$$

\subsection{Boundary Conditions}

The boundary conditions for the present problem are given as follows:

Temperature:

$T=0$ for $x=1, \quad T=1$ for $x=0$

$\frac{\partial T}{\partial n}=0$ on other walls (i.e., adiabatic).

Vorticity :

$\omega_{x}=0, \omega_{y}=-\frac{\partial V_{z}}{\partial x}, \omega_{z}=\frac{\partial V_{y}}{\partial x} \quad$ at $x=0$ and 1

$\omega_{x}=\frac{\partial V_{z}}{\partial y}, \omega_{y}=0, \omega_{z}=-\frac{\partial V_{x}}{\partial y} \quad$ at $y=0$ and 1

$\omega_{x}=-\frac{\partial V_{y}}{\partial z}, \omega_{y}=\frac{\partial V_{x}}{\partial z}, \omega_{z}=0 \quad$ at $\quad z=0$ and 1

Vector potential:

$\begin{array}{ll}\frac{\partial \psi_{x}}{\partial x}=\psi_{y}=\psi_{z}=0 & \text { at } x=0 \text { and } 1 \\ \psi_{x}=\frac{\partial \psi_{y}}{\partial y}=\psi_{z}=0 & \text { at } y=0 \text { and } 1 \\ \psi_{x}=\psi_{y}=\frac{\partial \psi_{z}}{\partial z}=0 & \text { at } z=0 \text { and } 1\end{array}$

Velocity :

$V_{x}=V_{y}=V_{z}=0 \quad$ on all walls

Electric potential:

$\frac{\partial \phi}{\partial n}=0$ on all walls

\section{Current density}

$\vec{J} \cdot \vec{n}=0$ on all walls

Where $\vec{n}$ is the unit vector normal to the wall.

\section{RESULTS AND DISCUSSION}

A finite volume based three dimensional numerical analysis on natural convection is performed on a differentially heated cubical enclosure filled with CNT-water nanofluid and subjected to an inclined external magnetic field. Numerical simulations are performed with single phase model and the results of processes of irreversibility are quantified by entropy generation. The FORTRAN language was used to solve the mathematical model. The result of entropy generation due to thermal, friction, Joule effect and total entropy generation are presented for various values of Rayleigh number $\left(10^{3} \leq \mathrm{Ra} \leq 10^{5}\right)$, Hartmann number $(0 \leq H a \leq 100)$, volumetric fractions of CNT $(0 \leq \varphi \leq 0.05)$ and angle of inclination of external magnetic force $\left(0^{\circ} \leq \alpha \leq 90^{\circ}\right)$. Bejan number is used as an indicator for identifying the influence parameter behind the entropy generation. The time step $\left(10^{-4}\right)$ and spatial mesh $\left(81^{3}\right)$ were used during the numerical analysis. The numerical simulations were performed till the convergence criterion given in the equation (22) was satisfied.

The grid independence test has been performed with, $R a=10^{5}$, $\varphi=0.05, \mathrm{Ha}=50$ and an angle of inclination of magnetic field as $90^{\circ}$. The tests were conducted for the spatial meshes of $61^{3}, 71^{3}, 81^{3}$ and $91^{3}$. The total entropy generation is selected as a sensitive parameter. The results of the grid sensitivity analysis were presented in Table 2 . The incremental increase in percentage of $N u_{a v}$ for the grid $81^{3}$ to $91^{3}$ is only $0.136 \%$. 
Table 2. Grid sensitivity analysis for: $\operatorname{Pr}=6.2, \mathrm{Ra}=10^{5}, \varphi=0.05, \mathrm{Ha}=$ 50 and $\alpha=90^{\circ}$

\begin{tabular}{cccc}
\hline $\begin{array}{c}\text { Grid } \\
\text { size }\end{array}$ & Nuavg & $\begin{array}{c}\text { Percentage } \\
\text { increase }\end{array}$ & $\begin{array}{c}\text { Incremental } \\
\text { increase }\end{array}$ \\
\hline $60^{3}$ & 7.4213 & - & - \\
$71^{3}$ & 7.368 & 0.7182 & - \\
$81^{3}$ & 7.31101 & 1.48613 & 0.77348 \\
$91^{3}$ & 7.301095 & 1.61974 & 0.13562 \\
\hline
\end{tabular}

Figure 2 illustrates the entropy generation inside the closed enclosure without the presence of magnetic force. The entropy generation is purely due to the effect of buoyancy forces and in the absence of magnetically induced Lorentz forces. When $R a=10^{5}$ and irreversibility coefficient is $10^{-5}$, the entropy generation due to thermal reflects only along the vertical walls with higher intensities reported on the diagonal corners. The high magnitude of inertia forces moved up the entropy generation on the right side wall. When CNT are 5\%, the intensity of thermally generated inertia forces are enhanced resulting three times increase in magnitude of entropy generation. The entropy generation due to friction is comparatively lower in magnitude for both the pure fluid and nanofluid. But entropy is generated on all the four walls with higher intensity on the vertical walls due to the presence of viscous forces.
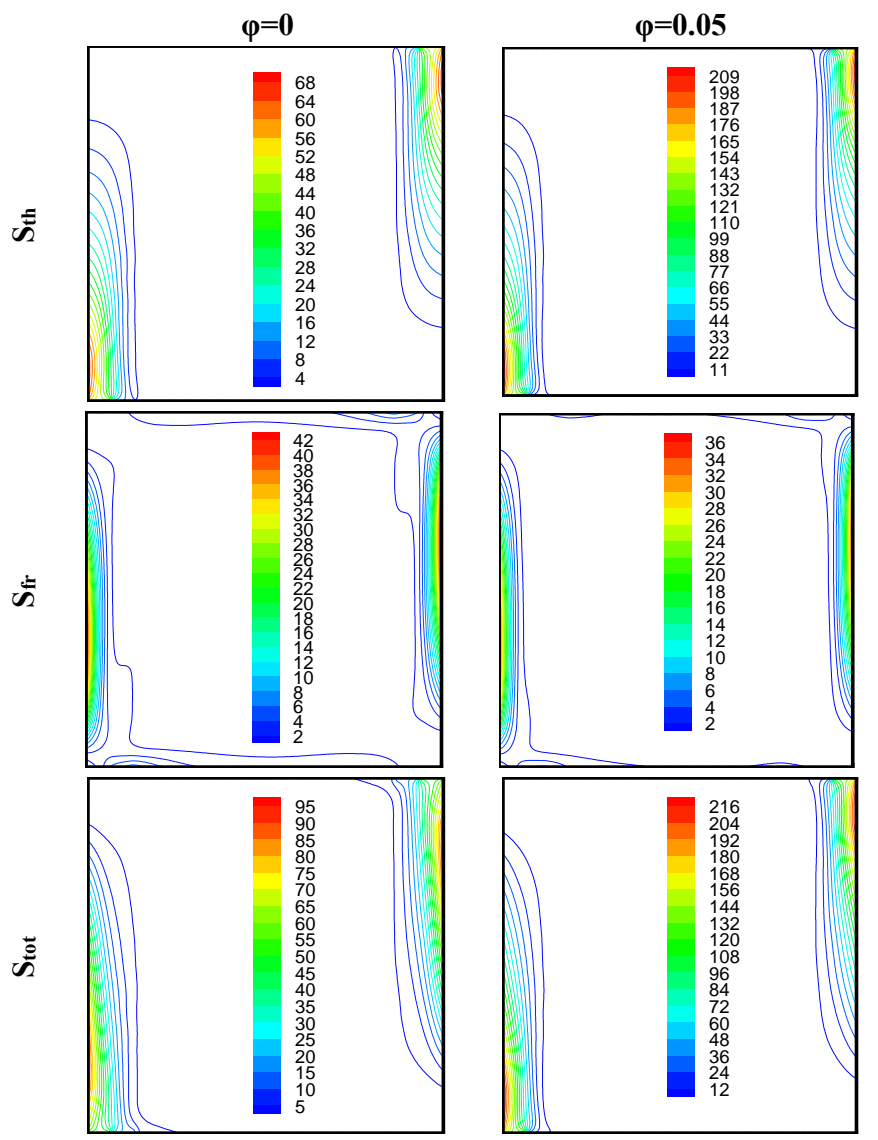

Fig. 2 Entropy generations at $\mathrm{z}=0.5$ plan for $\mathrm{Ra}=10^{5} ; \mathrm{Ha}=0, \varphi_{\mathrm{s}}=10^{-5}$

Fig. 3 illustrates the entropy generation due to higher Rayleigh number and Hartmann number when the angle of inclination of external magnetic field is $0^{\circ}$. At this angle, the magnetically induced Lorentz forces are orthogonal to the gravitational forces. The Lorentz forces are attracted towards the external magnetic force and acts against the direction of thermally induced buoyancy forces. This is clearly visible in the diagram representing the entropy generation due to the heat transfer. The reduction in intensity is nearly seven times when comparing with the results in the absence of a magnetic force. The generation is diagonally symmetric with higher intensities around the corners. The processes of irreversibility due to friction are evenly distributed along the four walls and its magnitude is extremely low.

The entropy generation due to electrical conductance is symmetrical along the vertical walls and extends up to the middle of the cavity. Its magnitude is in between the thermal and friction generated entropy. When the angle of inclination of the magnetic force is $30^{\circ}$, the entropy generation reduces slightly due to the suppressing effect by the Lorentz forces in all the cases and represented in fig. 4.

The entropy generation due to Joule effect is symmetrical and shifted towards the horizontal walls. When the angle of inclination of the magnetic force is $60^{\circ}$, the entropy generation is enhanced due to the reduction of Lorentz forces and presented in fig. 5. The entropy generation due to Joule effect is again shifted towards the vertical walls. When the angle of inclination of the magnetic force is moved to $90^{\circ}$ (fig. 6 ), the electrical conductivity is parallel to the gravitational forces. The net result is the reduction in magnitude of entropy generation but the Joule effect again shifted the entropy generation towards the horizontal walls. The addition of nanoparticles reduced the entropy generation by the Joule effect due to the increasing electrical conductance by the enlarged surface area of CNT.
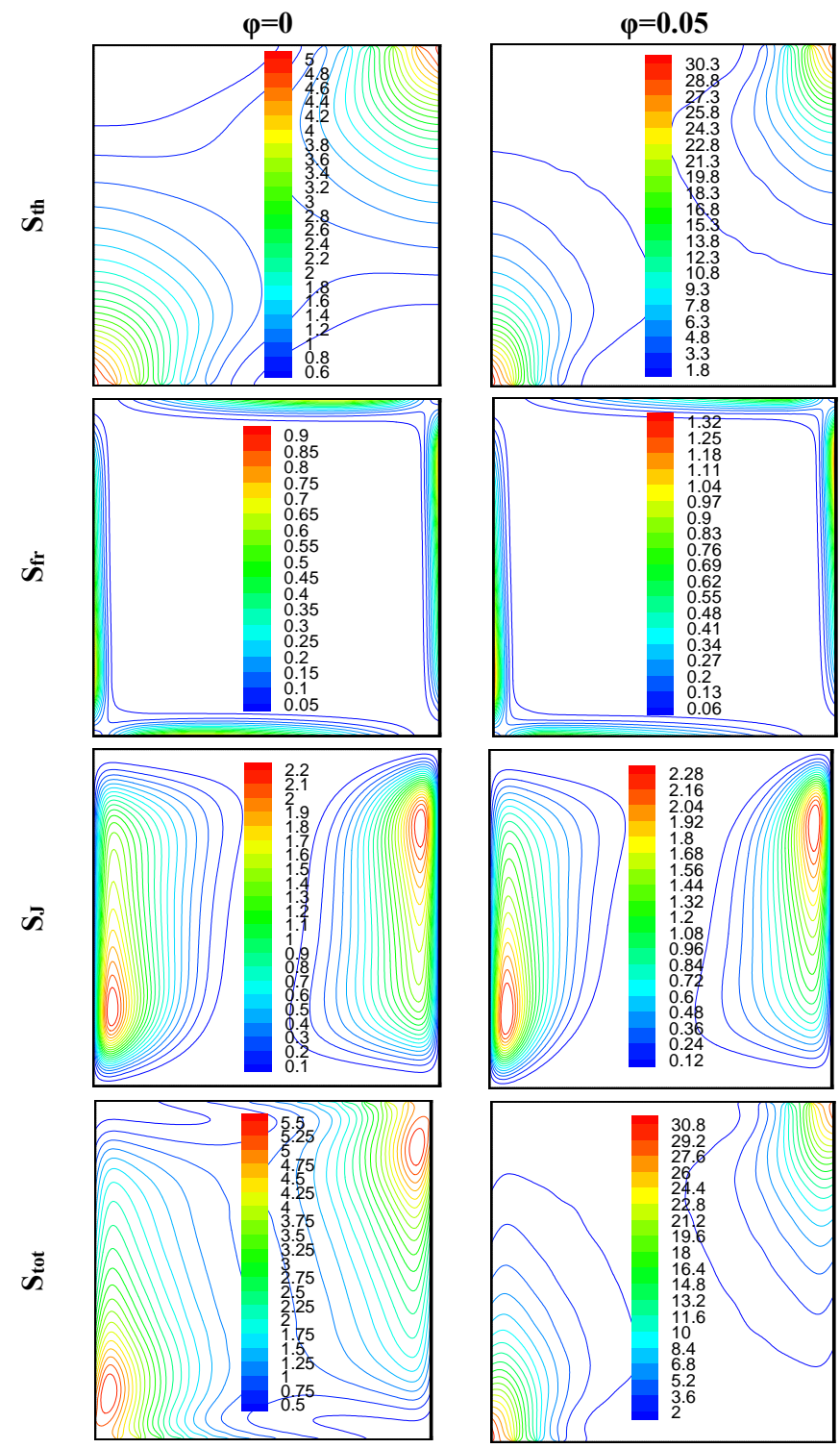

Fig. 3 Entropy generations at $\mathrm{z}=0.5$ plan for $\mathrm{Ra}=10^{5} ; \mathrm{Ha}=100$; $\varphi_{\mathrm{s}}=10^{-5} ; \alpha=0^{\circ}$ 
The isometric view of the total entropy generation inside the enclosure is illustrated in fig. 7. In the absence of magnetic field ( $\mathrm{Ha}$ $=0$ ), stratified layers are formed along the vertical walls with high magnitude of total entropy generated near the corners. By virtue of low buoyancy forces, the stratified layers are tends to move downwards on the left side wall and the highly generated buoyancy inside the enclosure tends to move the stratified layers upwards on the right side wall. The effect of the angle of inclination of the external magnetic force as discussed in the two-dimensional section is distinguishably visible in the iso-view of the total entropy generation when $\mathrm{Ha}=100$.

The effect of angle of inclination on the electric potential is more pronounced and is exemplifiable in the fig. 8. The increase in angle of inclination of the magnetic field has a prodigious effect on the electrical conductance and rotates the stratifications alternatively along the vertical and horizontal walls. The change of direction of Lorentz forces due to the inclination of the magnetic field is illustrated in the fig. 9.
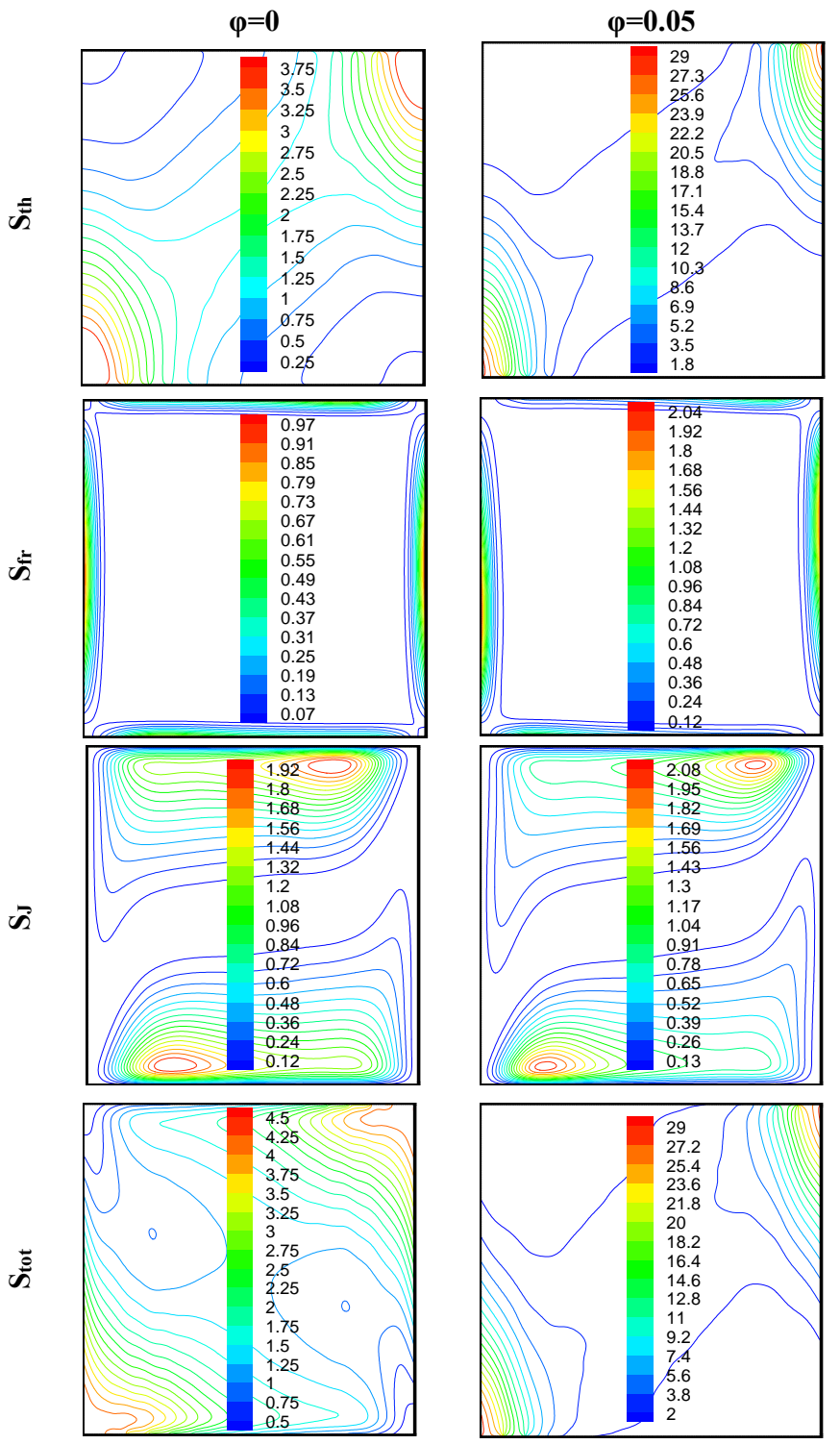

Fig. 4 Entropy generations at $\mathrm{z}=0.5$ plan for $\mathrm{Ra}=10^{5}, \varphi_{\mathrm{s}}=10^{-5} ; \mathrm{Ha}=$ $100 ; \alpha=30^{\circ}$

The Bejan number $(B e)$ indicates whether the thermally generated entropy is the dominant in the total entropy generation. Fig. 10 represents the Bejan number inside the cavity in the absence of magnetic field. Hence the flow is influenced either by thermal or friction only. The contour magnitude of greater than 0.5 indicates that the entropy generation is influenced by the thermal forces. When $R a=10^{5}$, buoyancy is maximum and it reflects on the $B e$ inside the cavity. The lines are densely backed around the walls. The vertical walls are exposed to more thermal convection than the horizontal walls with maximum intensity of $B e$ is reported in the zone between middle of the enclosure and top wall. The addition of CNT enhanced the intensity of buoyancy forces and increases the value of $\mathrm{Be}$.

The influence of magnetic field on entropy generation is illustrated in fig. 11. When $\alpha$ is zero, the Lorentz forces attracted the flow towards the magnetic force and suppress the effects of thermal and viscous forces. Since the horizontal walls and right wall are far away from the source of magnetic force, the effect of Lorentz forces are minimum on these walls and $B e$ is higher on these walls.
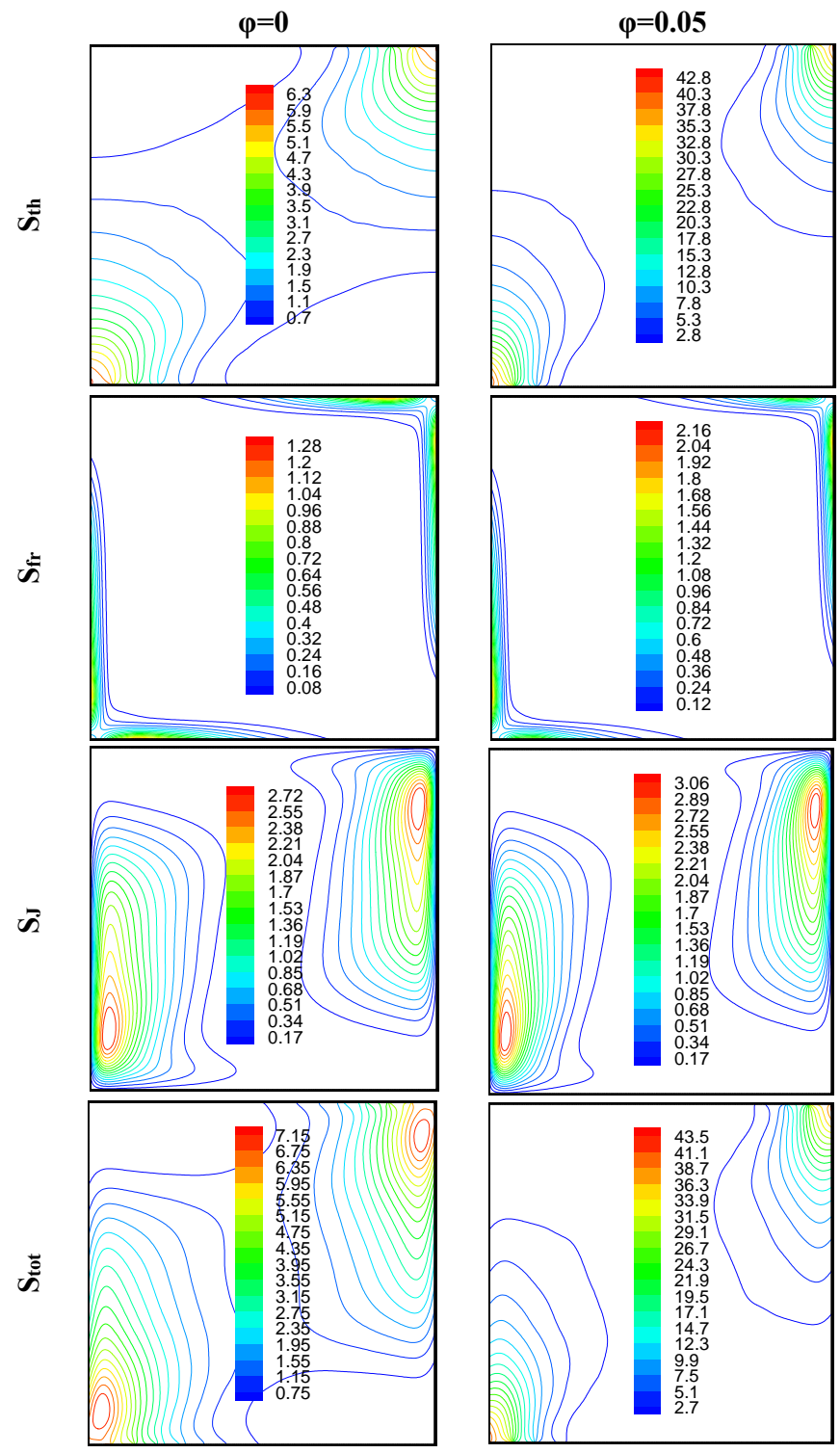

Fig. 5 Entropy generations at $\mathrm{z}=0.5$ plan for $\mathrm{Ra}=10^{5}, \varphi_{\mathrm{s}}=10^{-5}$; $\mathrm{Ha}=$ $100 ; \alpha=60^{\circ}$

Maximum intensity of $B e$ is reported at the middle of the enclosure. The introduction of nanoparticles increased the thermal convection and also the Bejan number. The contours are tilted diagonally towards the right wall. When the angle of inclination of magnetic force is increased, the direction of Lorentz forces are altered as indicated in the fig. 9. Depending upon the direction of magnetically induced Lorentz forces, the contours representing the $B e$ are rotated either towards vertically or horizontally. 

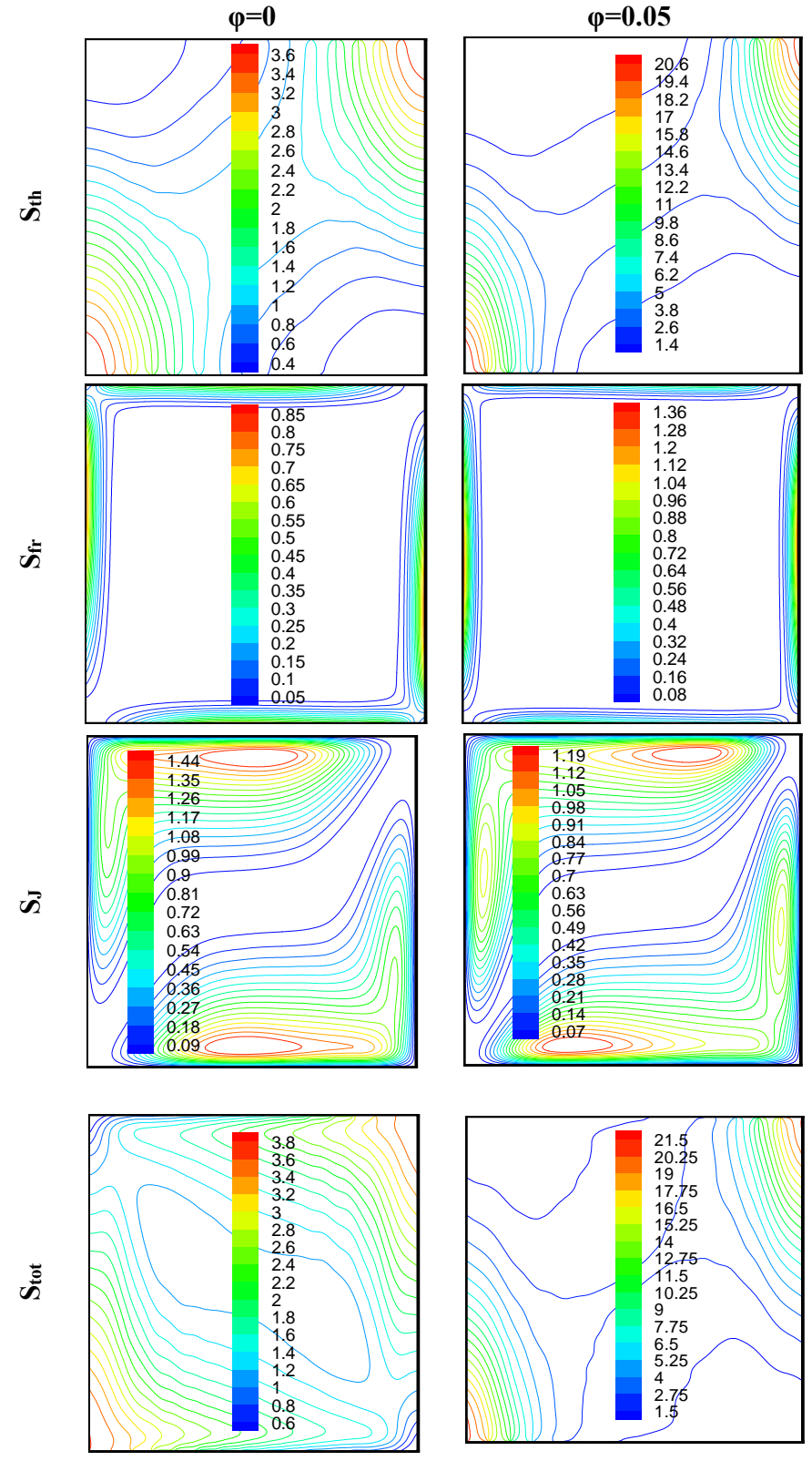

Fig. 6 Entropy generations for at $\mathrm{z}=0.5 \mathrm{Ra}=10^{5}, \varphi_{\mathrm{s}}=10^{-5} ; \mathrm{Ha}=100 ; \alpha$ $=90^{\circ}$

Fig. 12 describes the effect of the angle of inclination of magnetic field on the entropy generation due to thermal gradient. The angle of inclination does not have much influence at high $\mathrm{Ha}(100)$. When $\mathrm{Ha}$ is 50 , drastic changes are observed in the curves. The effect is clearly noticeable when $R a=10^{5}, \varphi=0.05$ and $H a=50$. The angle of inclination does not have much effect on the entropy generation due to friction when $R a$ is $10^{3}$ and $10^{4}$ (Fig. 13). Significant changes are observed in the graph at $R a=10^{5}$ for both the pure and nanofluid when $\mathrm{Ha}$ is 50. Fig. 14 shows the Joule effect on the entropy generation for various angles of inclination. The ferrous CNT particles are attracted by the magnetic force and hence entropy generation due to Joule effect decreases when $\varphi=0.05$. In most of the cases, apex of the entropy generation is observed when $\alpha$ is $60^{\circ}$. Fig. 15 indicates the total entropy generation for various angles of inclination. While for $R a=10^{3}$ and $10^{4}$, highest entropy generation is observed at $\alpha=60^{\circ}$ for both the pure and nanofluid. When $R a=10^{5}$, the highest entropy generation is shifted to $30^{\circ}$ angle of inclination. The effect of angle of inclination on the total entropy generation is more sensible when $\mathrm{Ha}=50$ than $\mathrm{Ha}=100$ and the variation of $\mathrm{S}_{\text {tot }}$ versus the inclination is similar to that od $\mathrm{S}_{\mathrm{th}}$, this is due to the produced Lorentz force that oppose the natural convection and thus reduces the velocity and $\mathrm{S}_{\mathrm{fr}}$. Fig. 16 represents the effect of the angles of inclination on the Bejan number. When $R a$ is increased, the Bejan number decreases. Even though the increasing of $R a$ increases the thermal forces, the cumulative effort of viscous and magneto forces reduced the Bejan number.

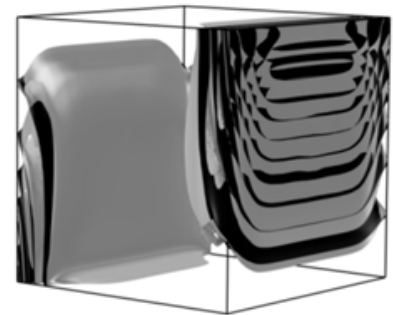

(a) $\mathrm{Ha}=\mathbf{0}$
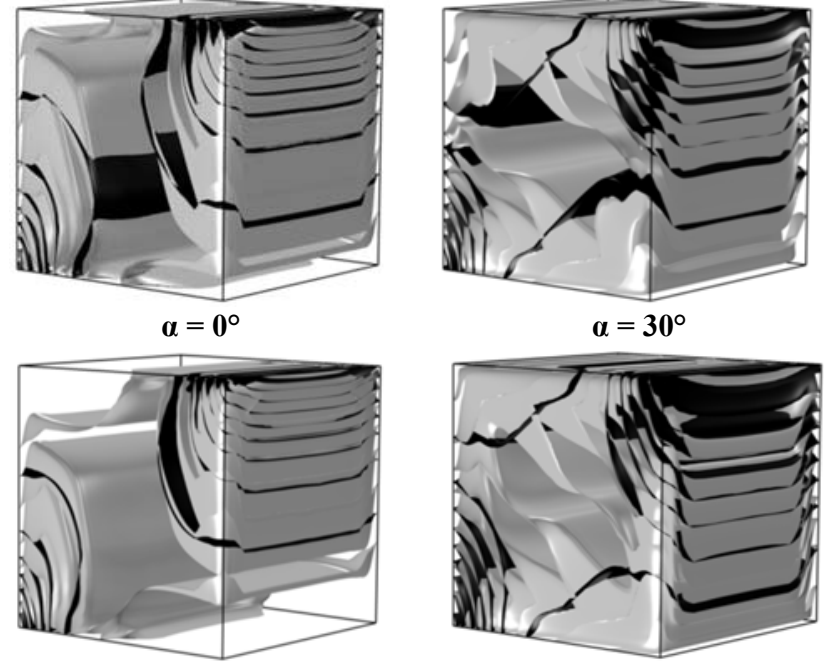

(b)

Fig. $7 \mathrm{~S}_{\text {tot }}$; $\mathrm{Ra}=10^{5}$ for $\varphi=0$ (gray), $\varphi=0.05$ (Black); (a) $\mathrm{Ha}=0$ and (b) $\mathrm{Ha}=100$ (for different magnetic field inclinations);
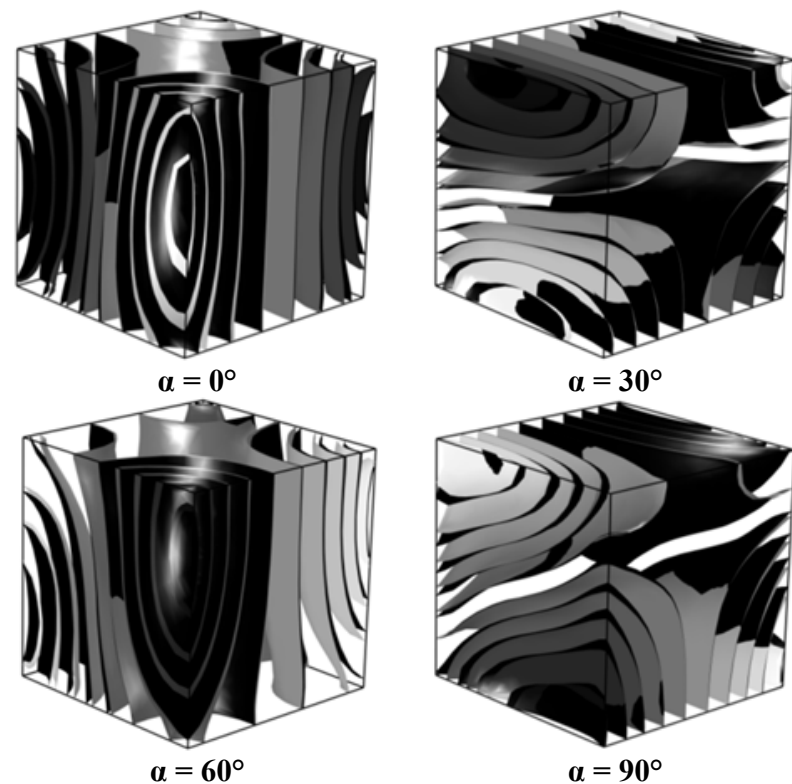

Fig. 8 Iso-view of electric potential $\mathrm{Ra}=10^{5} ; \mathrm{Ha}=100 ; \varphi=0$ (gray), $\varphi$ $=0.05$ (Black) 
The rate of declination is more in the pure fluid than the nanofluid. The angle of inclination of the magnetic field have a notorious effect at $R a=10^{5}$. For pure fluid, $B e$ declines up to $\alpha$ is $30^{\circ}$ and then surges when $\mathrm{Ha}=50$. The declination is up to $60^{\circ}$ when $\mathrm{Ha}$ is increased to 100. For the nanofluid, the declination is up to $30^{\circ}$ for both the Hartmann number due to the enhancement of thermal generation.

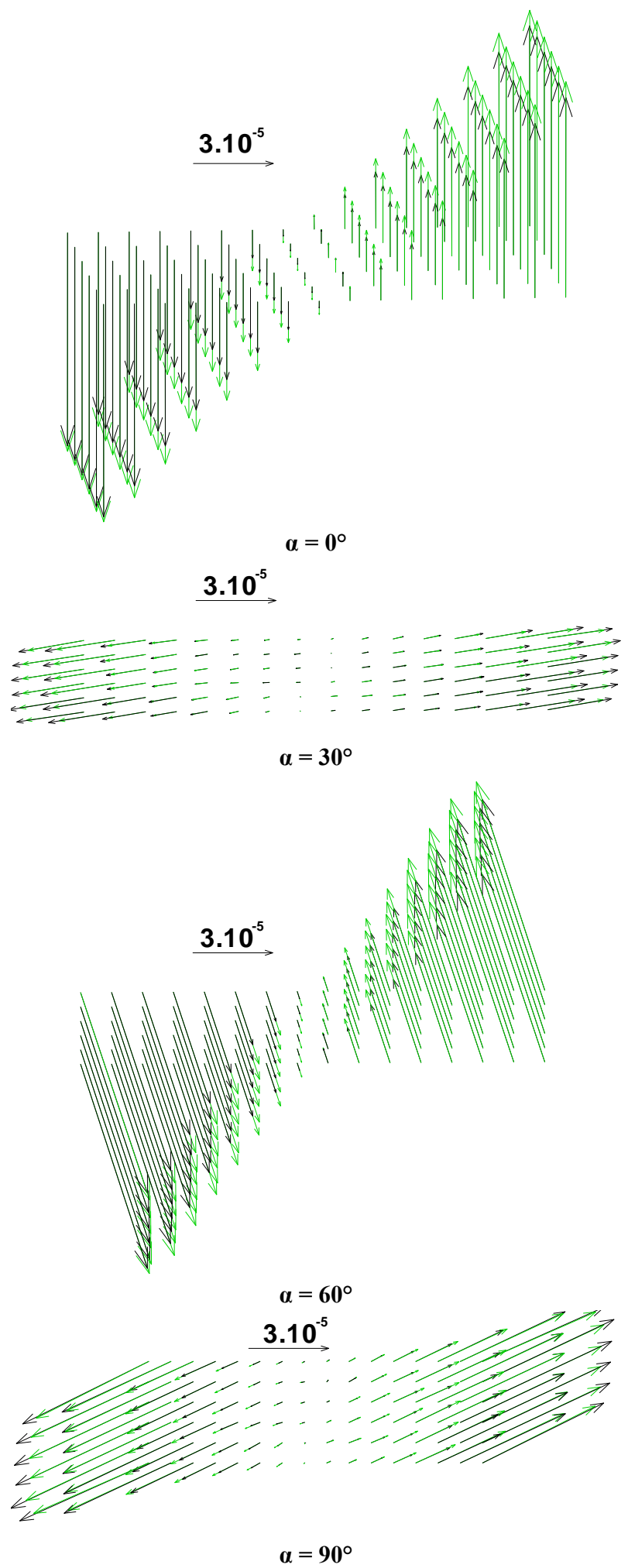

Fig. 9 Lorentz force at $\mathrm{y}=0.5$ plan $\varphi=0$ (Green), $\varphi=0.05$ (Black)
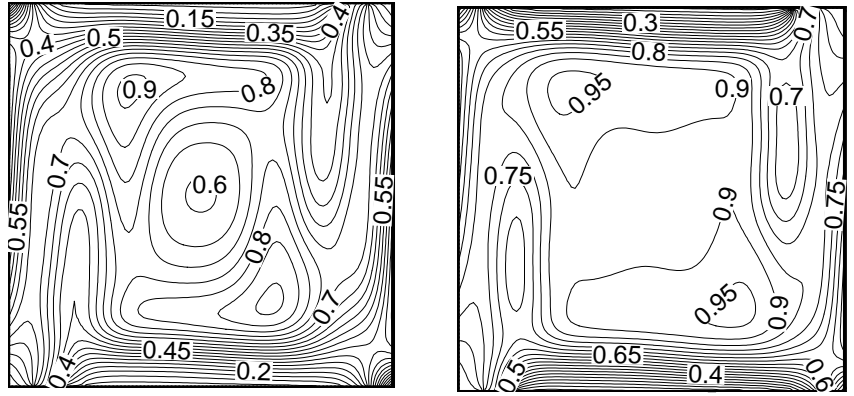

Fig. 10 Bejan Number for $\mathrm{Ha}=0$ and $\mathrm{Ra}=10^{5}$
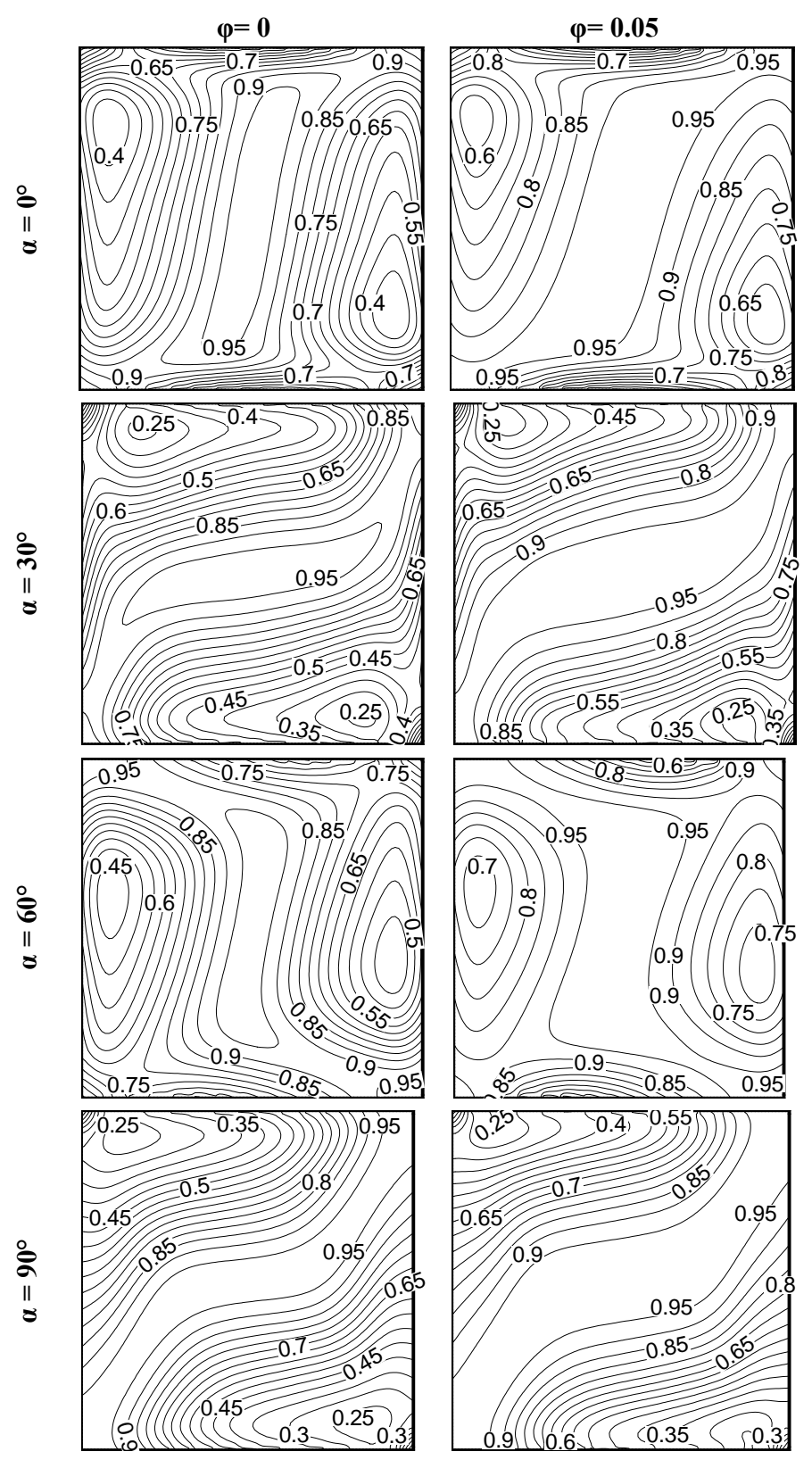

Fig. 11 Bejan Number for $\mathrm{Ha}=100$ and $\mathrm{Ra}=10^{5}$ 


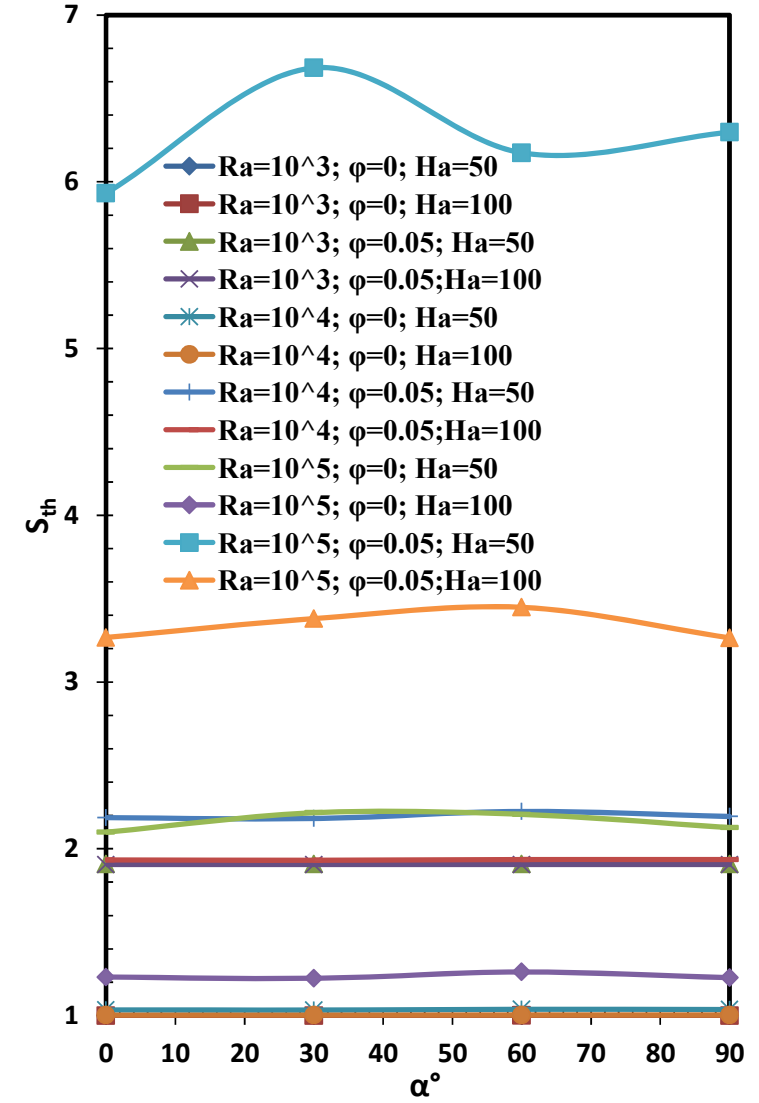

Fig. 12 Thermal Entropy versus Angle of inclination

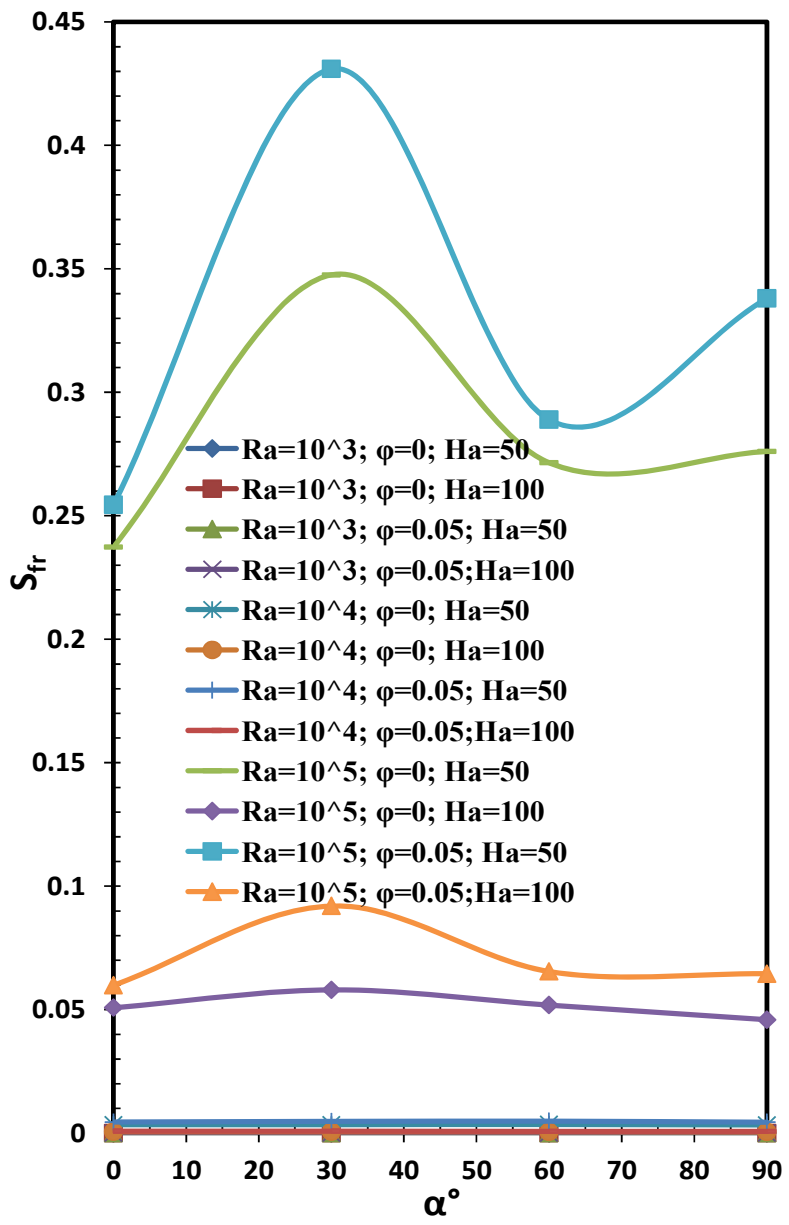

Fig. 13 Entropy due to friction versus Angle of inclination

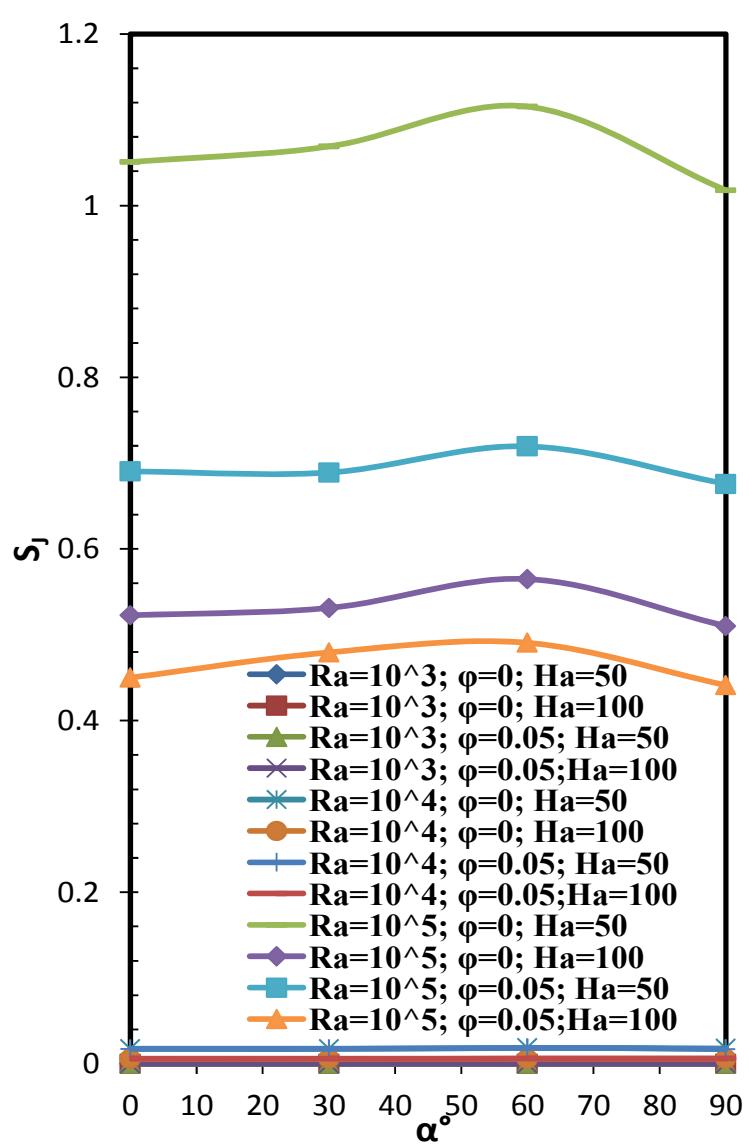

Fig. 14 Joule effect entropy versus Angle of inclination

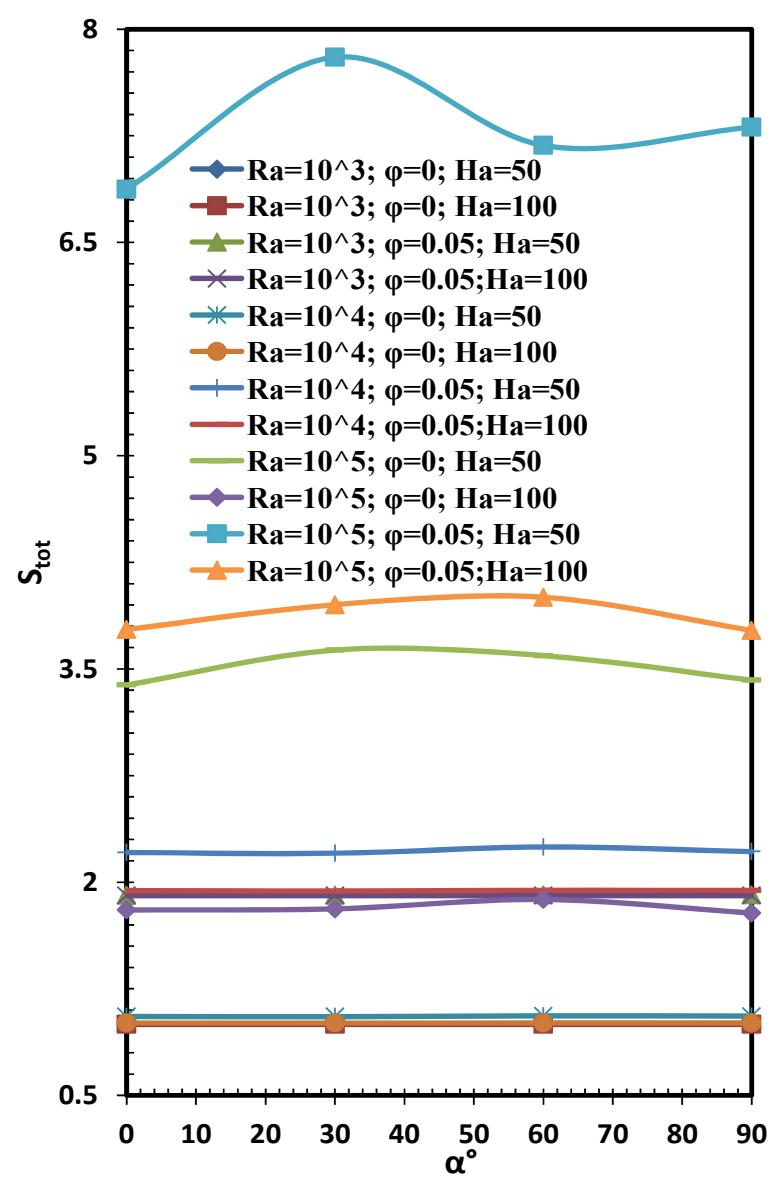

Fig. 15 Total Entropy versus Angle of inclination 


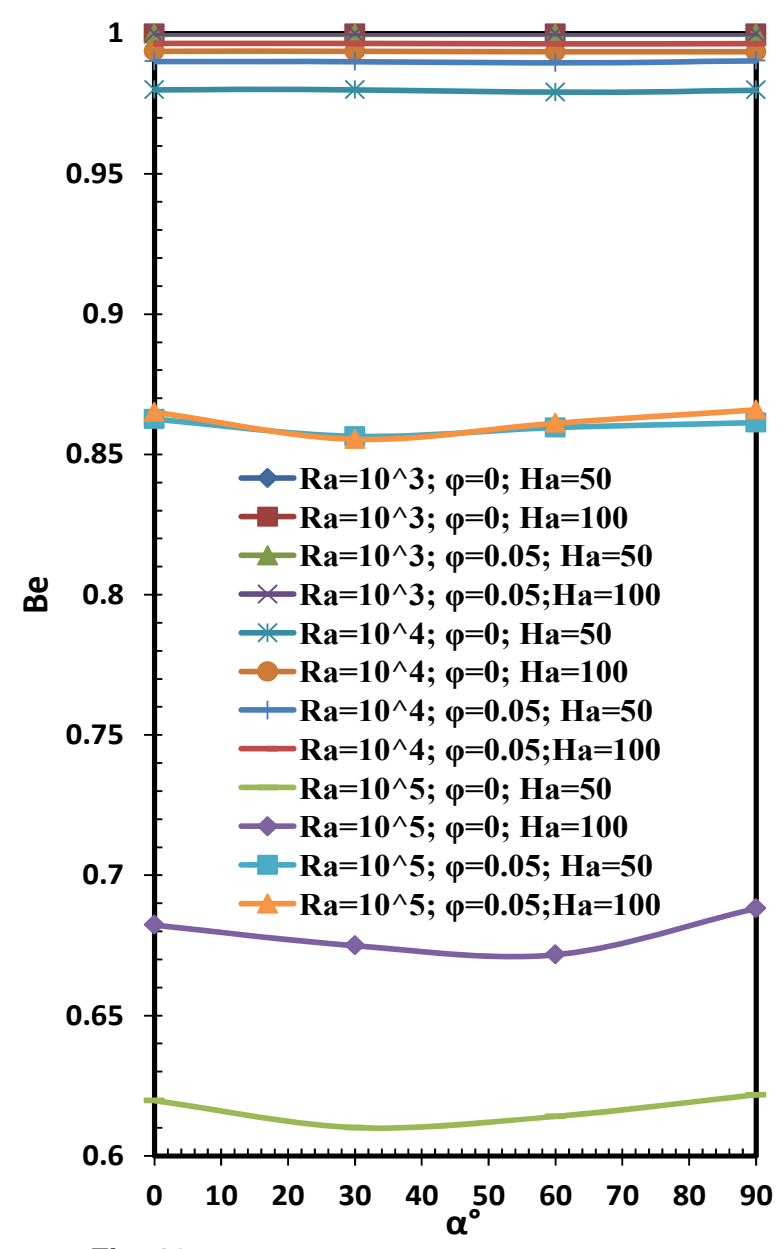

Fig. 16 Bejan number versus Angle of inclination

\section{CONCLUSIONS}

Three dimensional numerical simulations were performed on the cubical cavity filled with CNT-water nanofluid and exposed to external magnetic field at different angle of inclinations. The effects of nanoparticles, angle of inclination of magnetic field, Rayleigh number and Hartmann number on natural convection were investigated. Based on the research, the following findings are obtained.

- The effect of angle of inclination is more pronounced when Rayleigh number is $10^{5}$.

- At high Ra $\left(10^{5}\right)$, the increase in percentage of CNT increased the effect of angle of inclination for both the pure and nanofluid.

- The effect of angle of inclination on the total entropy generation is more sensible when $\mathrm{Ha}=50$.

- The entropy generation due to Joule effect is shifted alternatively towards the vertical and horizontal walls when the angle of inclination of the magnetic field is increased

- The influence of magnetic field increased the Bejan number during the increase of $\varphi$ for all the Rayleigh numbers.

\section{NOMENCLATURE}

$\vec{B}$

Magnetic field $\left(=\vec{B}^{\prime} / B_{0}\right)$

$B e \quad$ Bejan number

$C_{p} \quad$ Specific heat at constant pressure $(\mathrm{J} / \mathrm{kg} . \mathrm{K})$

$\vec{E} \quad$ Dimensionless electric field

$\vec{e}_{B} \quad$ Direction of magnetic field $g \quad$ Gravitational acceleration $\left(\mathrm{m} / \mathrm{s}^{2}\right)$

$\vec{J} \quad$ Dimensionless density of electrical current

$k \quad$ Thermal conductivity (W/m.K)

$l \quad$ Enclosure width

$n \quad$ unit vector normal to the wall.

$N_{s} \quad$ Dimensionless local generated entropy

$\mathrm{Nu} \quad$ Local Nusselt number

Pr Prandtl number

Ra Rayleigh number

$S^{\prime}{ }_{\text {gen }} \quad$ Generated entropy $(\mathrm{kJ} / \mathrm{kg} . \mathrm{K})$

$t \quad$ Dimensionless time $\left(t^{\prime} . \alpha / l^{2}\right)$

$T \quad$ Dimensionless temperature $\left[\left(T^{\prime}-T^{\prime}{ }_{c}\right) /\left(T^{\prime}{ }_{h}-T^{\prime}{ }_{c}\right)\right]$

$T^{\prime}{ }_{c} \quad$ Cold temperature $(\mathrm{K})$

$T^{\prime}{ }_{h} \quad$ Hot temperature (K)

$T_{o} \quad$ Bulk temperature $\left[T_{o}=\left(T^{\prime}{ }_{c}+T^{\prime}{ }_{h}\right) / 2\right] \quad(\mathrm{K})$

$\vec{V} \quad$ Dimensionless velocity vector $\left(\vec{V}^{\prime} \cdot l / \alpha\right)$

$x, y, z \quad$ Dimensionless coordinates $\left(x^{\prime} / l, y^{\prime} / l, z^{\prime} / l\right)$

\section{Greek symbols}

$\alpha \quad$ Thermal diffusivity $\left(\mathrm{m}^{2} / \mathrm{s}\right)$

$\beta \quad$ Thermal expansion coefficient $(1 / \mathrm{K})$

$\rho \quad$ Density $\left(\mathrm{kg} / \mathrm{m}^{3}\right)$

$\mu \quad$ Dynamic viscosity (kg./m.s)

$v \quad$ Kinematic viscosity $\left(\mathrm{m}^{2} / \mathrm{s}\right)$

$\varphi \quad$ Nanoparticle volume fraction

$\gamma \quad$ Cavity inclination

$\sigma \quad$ Electrical conductivity

$\vec{\psi} \quad$ Dimensionless vector potential $\left(\vec{\psi}^{\prime} / \alpha\right)$

$\vec{\omega} \quad$ Dimensionless vorticity $\left(\vec{\omega}^{\prime} \cdot \alpha / l^{2}\right)$

$\Delta T \quad$ Dimensionless temperature difference

\section{Subscripts}

av Average

f Fluid

fr Friction

j Joule effect

nf Nanofluid

$\mathrm{s} \quad$ solid (nanoparticle)

$\mathrm{x}, \mathrm{y}, \mathrm{z} \quad$ Cartesian coordinates

\section{Superscript}

,

Dimensional variable

\section{REFERENCES}

Abolbashari M.H., N. Freidoonimehr, Nazari F. and Rashidi M.M., 2014, "Entropy Analysis For An Unsteady MHD Flow Past a Stretching Permeable Surface in Nanofluid," Powder Technology, 267, 256-267. http://dx.doi.org/10.1016/j.powtec.2014.07.028

Abu-Nada E. and Oztop H.F., 2009 "Effects of Inclination Angle on Natural Convection in Enclosures Filled with Cu-water Nanofluid," International Journal of Heat and Fluid Flow, 30, 669-678. http://dx.doi.org/10.1016/j.ijheatfluidflow.2009.02.001

Aghaei A., Khorasanizadeh H., Sheikhzadeh G., and Abbaszadeh M., 2016 "Numerical Study of Magnetic Field on Mixed Convection and Entropy Generation of Nanofluid in a Trapezoidal Enclosure," Journal of Magnetism and Magnetic Materials, 403, 133-145. http://dx.doi.org/10.1016/j.jmmm.2015.11.067 
Bejan A., 1979, "A Study of Entropy Generation in Fundamental Convective Heat Transfer," Journal of Heat Transfer, 101, 718-725, 1979.

http://dx.doi.org/10.1115/1.3451063

Cho C.C., 2016, "Influence of Magnetic Field on Natural Convection and Entropy Generation in $\mathrm{Cu}$-Water Nanofluid-Filled Cavity with Wavy Surfaces," International Journal of Heat and Mass Transfer, 101, 637647.

http://dx.doi.org/10.1016/j.ijheatmasstransfer.2016.05.044

Ding Y., Alias H., Wen D., and Williams R.A., 2006 "Heat Transfer of Aqueous Suspensions of Carbon Nanotubes (CNT) Nanofluids," International Journal of Heat and Mass Transfer, 49, 240-250. http://dx.doi.org/10.1016/j.ijheatmasstransfer.2005.07.009

Ellahi R., Hassan M., and Zeeshan A., 2015 "Shape Effects of Nanosize Particles in $\mathrm{Cu}-\mathrm{H}_{2} \mathrm{O}$ Nanofluid on Entropy Generation," International Journal of Heat and Mass Transfer, 81, 449-456.

http://dx.doi.org/10.1016/j.ijheatmasstransfer.2014.10.041

Esfe M.H., Akbar A., Arani A., Yan W.M., Ehteram H., Aghaie A., and Afrand M., 2016, "Natural Convection in a Trapezoidal Enclosure Filled with Carbon Nanotube-EG-Water Nanofluid," International Journal of Heat and Mass Transfer, 92, 76-82.

http://dx.doi.org/10.1016/j.ijheatmasstransfer.2015.08.036

Glory J., Bonettid M. Helezen M., Mayne M. Hermite L., and Reynaud C., 2008, "Thermal and Electrical Conductivities of Water-Based Nanofluids Prepared with Long Multiwalled Carbon Nanotubes," Journal of Applied Physics, 103(094309), 1-7.

http://dx.doi.org/10.1063/1.2908229

Hayat T., Imtiaz M., and Alsaedi A.. 2015, "MHD 3D Flow of Nanofluid in Presence of Convective Conditions," Journal of Molecular Liquids, 212, 203-208.

http://dx.doi.org/10.1016/j.molliq.2015.09.012

Ibanez G., Cuevas S., and De Haro M.L., 2006, "Optimization of a Magnetohydrodynamic Flow Based on the Entropy Generation Minimization Method," International Communications in Heat and Mass Transfer, 33, 295-301.

http://dx.doi.org/10.1016/j.icheatmasstransfer.2005.12.003

Job V. M. and Gunakala S. R., 2016, "Unsteady MHD Free Convection Nanofluid Flows Within a Wavy Trapezoidal Enclosure with Viscous and Joule Dissipation Effects," Numerical Heat Transfer, Part A, 69(4), 421-443.

http://dx.doi.org/10.1080/10407782.2015.1080946

Kahveci K., 2010, "Buoyancy Driven Heat Transfer of Nanouids in a Tilted Enclosure," Journal of Heat Transfer, 132, 062501.

http://dx.doi.org/10.1115/1.4000744

Kalidasan K. and Kanna P.R., 2016, "Effective Utilization of MWCNTWater Nanofluid for the Enhancement of Laminar Natural Convection Inside the Open Square Enclosure," Journal of the Taiwan Institute of Chemical Engineers, 65, 331-340.

http://dx.doi.org/10.1016/j.jtice.2016.05.035

Kefayati G.H.R., 2016, "Simulation of Double Diffusive MHD (Magnetohydrodynamic) Natural Convection and Entropy Generation in an Open Cavity Filled with Power-Law Fluids in the Presence of Soret and Dufour Effects (Part II: Entropy Generation)," Energy, 107, 917959.

http://dx.doi.org/10.1016/j.energy.2016.05.044
Khorasanizadeh H., Nikfar M., and Amani J., 2013 "Entropy Generation of Cu-Water Nanofluid Mixed Convection in a Cavity," European Journal of Mechanics B/Fluids, 37, 143-152.

http://dx.doi.org/10.1016/j.euromechflu.2012.09.002

Kolsi L., Abidi A., Borinjini M.N., and Ben Aissia H., 2010 "The Effect of an External Magnetic Field on the Entropy Generation in ThreeDimensional Natural Convection," Thermal Science, 14, 341-352. http://dx.doi.org/10.2298/TSCI1002341K

Kolsi L., 2016, "MHD Mixed Convection and Entropy Generation in a 3D Lid-Driven Cavity," Frontiers in Heat and Mass Transfer, 7, 26. http://dx.doi.org/10.5098/hmt.7.26

Kolsi L., Kalidasan K., Alghamdi A., Borjini M.N., and Kanna P. R. 2016 "Natural Convection and Entropy Generation in a Cubical Cavity with Twin Adiabatic Blocks Filled by Aluminum Oxide Water Nanofluid," Numerical Heat Transfer, Part A: Applications, 70, 242259.

http://dx.doi.org/10.1080/10407782.2016.1173478

Maatki C., Ghachem K., Kolsi L., Borjini M. N., and Ben Aissia H., 2014, "Entropy Generation of Double Diffusive Natural Convection in a Three Dimensional Differentially Heated Enclosure," International Journal of Engineering, 2:215-226.

Mahian O., Mahmud S., and Heris S.Z.. "Analysis of Entropy Generation Between Co-Rotating Cylinders Using Nanofluids," Energy, 44, 438446, 2012.

http://dx.doi.org/10.1016/j.energy.2012.06.009

Mahmoudi A. H., Pop I., Shahi M., and Talebi F., 2013 “MHD Natural Convection and Entropy Generation in a Trapezoidal Enclosure Using $\mathrm{Cu}$-Water Nanofluid," Computers and Fluids, 72, 46-62.

http://dx.doi.org/10.1016/j.compfluid.2012.11.014

Mahmud S. and Fraser R.A., 2004 "Magnetohydrodynamic Free Convection and Entropy Generation in a Square Porous Cavity," International Journal of Heat and Mass Transfer, 47, 3245-3256. http://dx.doi.org/10.1016/j.ijheatmasstransfer.2004.02.005

Mejri I., Mahmoudi A., Abbassi M.A., and Omri A., 2014 "Magnetic Field Effect on Entropy Generation in a Nanofluid-Filled Enclosure with Sinusoidal Heating on Both Side Walls," Powder Technology, 266, 340 353.

http://dx.doi.org/10.1016/j.powtec.2014.06.054

Mojumder S., Rabbi K.M., Saha S., Hasan M.N., and Saha S.C., 2016 "Magnetic Field Effect on Natural Convection and Entropy Generation in a Half-Moon Shaped Cavity With Semi-Circular Bottom Heater Having Different Ferrouid Inside," Journal of Magnetism and Magnetic Materials, 407, 412-424.

http://dx.doi.org/10.1016/j.jmmm.2016.01.046

Oztop H.F. and Al-Salem K., 2012 "A Review on Entropy Generation in Natural and Mixed Convection Heat Transfer for Energy Systems," Renewable and Sustainable Energy Reviews, 16, 911-920. http://dx.doi.org/10.1016/j.rser.2011.09.012

Seth G. S., Sharma R., and Kumbhakar B., 2016 "Heat and Mass Transfer Effects on Unsteady MHD Natural Convection Flow of a Chemically Reactive and Radiating Fluid Through a Porous Medium Past a Moving Vertical Plate with Arbitrary Ramped Temperature," Journal of Applied Fluid Mechanics, 9, 103 - 117.

Xue, Q.Z., 2005, "Model for Thermal Conductivity of Carbon NanotubeBased Composites," Physica B, 368:302-307.

http://dx.doi.org/10.1016/j.physb.2005.07.024 